Vietnam Journal of Mechanics, VAST, Vol.30, No. 3 (2008), pp. 185 - 194

\title{
THERMAL BUCKLING OF IMPERFECT FUNCTIONALLY GRADED CYLINDRICAL SHELLS ACCORDING TO WAN-DONNELL MODEL
}

\author{
Hoang Van Tung \\ Hanoi Architectural University, Vietnam \\ Nguyen Dinh Duc \\ Vietnam National University, Hanoi
}

\begin{abstract}
A thermal buckling analysis of imperfect circular cylindrical shells of functionally graded material is considered. The material properties are assumed varying as a power form of thickness coordinate variable. The Donnell equilibrium and stability equations are considered and the Wan-Donnell model for initial geometrical imperfection is adopted. The thermal loads include the uniform temperature rise and nonlinear temperature change across the thickness of shell. A closed form solution for the thermal buckling of simply supported cylindrical FG shell under the described thermal loads is obtained. The influences of the relative thickness, the imperfection size and the power law index on buckling thermal loads are all discussed.
\end{abstract}

\section{INTRODUCTION}

The initial geometric imperfections are inherent in many real structures. Therefore, many investigations are conducted on the stability analysis of imperfect structures. Elastic, plastic, and creep buckling of imperfect cylinders under mechanical and thermal loads is studied by Eslami and Shariyat [3]. Mossavarali et al. studied the thermoelastic buckling of isotropic and orthotropic plates with imperfections [8, 9]. Murphy and Ferreira [10] investigated thermal buckling analysis of clamped rectangular plates based on the energy consideration. They determined the ratio of the critical temperature for a perfect flat plate to that one for an imperfect plate as a function of the initial imperfection size. The study includes experimental results. Eslami and Shahsiah [2] reported thermal buckling of imperfect circular cylindrical shells made of isotropic materials. They used the WanDonnell and Koiter models to describle initial geometrical imperfection.

The development of new materials with new constitutive models have necessitated more research in the area of stability analysis. Functionally graded materials (FGMs) are of these new and high-temperature resistant materials in which material constitution vary continuously across the thickness of a structure. Some works about the stability of FGM structures are introduced in the following. Javaheri and Eslami $[4,5,6]$ reported mechanical and thermal buckling of rectangular functionally graded plates. They used energy method and mainly reached to the closed-form solutions. The research on thermal buckling of functionally graded cylindrical shells is introduced by Shahsiah and Eslami $[12,13]$. Shen [14] represented thermal postbuckling behavior of functionally graded cylindrical shells with dependent temperature properties. He considered initial geometrical imperfections in the analysis. Wu et al. [16] studied the thermoelastic stability of functionally graded 
cylindrical shells by using the Donnell shell theory. They obtained closed-form solutions for the critical buckling loads with three types of thermal loads being uniform temperature rise, linear temperature change and nonlinear thermal gradient through the thickness direction of shell.

In the present article, mainly motivated by Eslami and Shahsiah [2], the influence of geometrical imperfections on thermal instability of FG shells is investigated. The shell is graded through the thickness direction according to a power law function. The Donnell stability equations are considered and the Wan-Donnell model for axisymmetric imperfection is adopted. The shell is assumed to be simply supported at two ends. The buckling of shell under two types of thermal loads are obtained. The thermal loads are assumed to be uniform temperature rise and nonlinear thermal gradient through the thickness direction. Closed form solutions are given for two types of the assumed thermal loads. The influences of imperfection size, the relative thickness and the power law index on the critical thermal loads are considered and discussed.

\section{FUNCTIONALLY GRADED SHELL}

Functionally graded materials (FGMs) are microscopically inhomogeneous materials in which the mechanical properties vary smoothly and continuously through the thickness. This is achieved by gradually changing the volume fraction of the constituent materials. These materials are made from a mixture of ceramic and metal or a combination of different metals [11]. The ceramic part provides high-temperature resistance due to its low thermal conductivity and metal part prevents fracture because of thermal loadings. FGMs are able to withstand ultra high temperature environments and extremly large thermal gradients while maintaining their structural integrity. FGMs have found diverse engineering applications in aerospace structures, nuclear reactors, chemical plants, etc.

The functionally graded (FG) cylindrical shell is assumed to be a thin shell of length $L$, thickness $h$ and radius $R$. The $x$-axis is taken along a generatrix, the circumferential length subtends an angle $\theta$, and the $z$-axis is directed radially inwards. We assume that the modulus of elasticity $E$, the coefficient of thermal expansion $\alpha$ and conductivity $K$ change in the thickness direction $z$, while the Poisson ratio $\nu$ is assumed to be constant. The material properties of FG shell are introduced as $[13,16]$.

$$
\begin{aligned}
& E(z)=E_{m}+E_{c m}\left(\frac{2 z+h}{2 h}\right)^{k}, \\
& \alpha(z)=\alpha_{m}+\alpha_{c m}\left(\frac{2 z+h}{2 h}\right)^{k}, \\
& K(z)=K_{m}+K_{c m}\left(\frac{2 z+h}{2 h}\right)^{k}, \\
& \nu(z)=\nu
\end{aligned}
$$

where

$$
E_{c m}=E_{c}-E_{m}, \alpha_{c m}=\alpha_{c}-\alpha_{m}, K_{c m}=K_{c}-K_{m},
$$

and subscripts " $m$ " and " $c$ " refer to the metal and ceramic constituents, respectively. The variable $z$ is the thickness coordinate $(-h / 2 \leqslant z \leqslant h / 2)$, where $h$ is the thickness of the shell and $k$ is the power law index which takes values greater than or equal to zero. The 
variation of the composition of ceramic and metal is linear for $k=1$. The value of $k$ equal to zero represents a fully ceramic shell.

\section{ANALYSIS}

The constitutive relations are written as [16]

$$
\begin{aligned}
N_{x} & =\frac{E_{1}}{1-\nu^{2}}\left(\varepsilon_{x m}+\nu \varepsilon_{\theta m}\right)+\frac{E_{2}}{1-\nu^{2}}\left(k_{x}+\nu k_{\theta}\right)-\frac{\Phi}{1-\nu}, \\
N_{\theta} & =\frac{E_{1}}{1-\nu^{2}}\left(\varepsilon_{\theta m}+\nu \varepsilon_{x m}\right)+\frac{E_{2}}{1-\nu^{2}}\left(k_{\theta}+\nu k_{x}\right)-\frac{\Phi}{1-\nu}, \\
N_{x \theta} & =\frac{E_{1}}{2(1+\nu)} \gamma_{x \theta m}+\frac{E_{2}}{1+\nu} k_{x \theta} . \\
M_{x} & =\frac{E_{2}}{1-\nu^{2}}\left(\varepsilon_{x m}+\nu \varepsilon_{\theta m}\right)+\frac{E_{3}}{1-\nu^{2}}\left(k_{x}+\nu k_{\theta}\right)-\frac{\Theta}{1-\nu}, \\
M_{\theta} & =\frac{E_{2}}{1-\nu^{2}}\left(\varepsilon_{\theta m}+\nu \varepsilon_{x m}\right)+\frac{E_{3}}{1-\nu^{2}}\left(k_{\theta}+\nu k_{x}\right)-\frac{\Theta}{1-\nu}, \\
M_{x \theta} & =\frac{E_{2}}{2(1+\nu)} \gamma_{x \theta m}+\frac{E_{3}}{1+\nu} k_{x \theta} .
\end{aligned}
$$

where

$$
\begin{aligned}
E_{1} & =E_{m} h+\frac{E_{c m} h}{k+1}, \\
E_{2} & =\frac{k E_{c m} h^{2}}{2(k+1)(k+2)}, \\
E_{3} & =\frac{1}{12} E_{m} h^{3}+E_{c m} h^{3}\left[\frac{1}{k+3}-\frac{1}{k+2}+\frac{1}{4(k+1)}\right], \\
\Phi & =\int_{-h / 2}^{h / 2}\left[E_{m}+E_{c m}\left(\frac{2 z+h}{2 h}\right)^{k}\right]\left[\alpha_{m}+\alpha_{c m}\left(\frac{2 z+h}{2 h}\right)^{k}\right] \Delta T(x, y, z) d z, \\
\Theta & =\int_{-h / 2}^{h / 2}\left[E_{m}+E_{c m}\left(\frac{2 z+h}{2 h}\right)^{k}\right]\left[\alpha_{m}+\alpha_{c m}\left(\frac{2 z+h}{2 h}\right)^{k}\right] \Delta T(x, y, z) z d z .
\end{aligned}
$$

In the above equations, $N_{i j}$ and $M_{i j}$ are force and moment resultants, respectively, $\varepsilon_{x m}, \varepsilon_{\theta m}$ are the extension strains and $\gamma_{x \theta m}$ is shear strain at the middle surface of the shell. The curvature changes are shown by $k_{i j}$.

The strain displacement relations according to Donnell's assumption [1] as follows.

$$
\begin{array}{ll}
\varepsilon_{x m}=u_{, x}+\frac{1}{2} w_{, x}^{2}, & \varepsilon_{\theta m}=\left(v_{, \theta}+w\right) / R+w_{, \theta}^{2} / 2 R^{2}, \\
\gamma_{x \theta m}=u_{, \theta} / R+v_{, x}+w_{, x} w_{, \theta} / R, & k_{x}=-w_{, x x} \\
k_{\theta}=-w_{, \theta \theta} / R^{2}, & k_{x \theta}=-w_{, x \theta} / R,
\end{array}
$$

where $u, v, w$ are the axial, circumferential, and deflection displacements of the shell and the comma symbols partial derivative. 
By using Donnell shell theory [1], the equilibrium equations of FG cylindrical shell are derived as

$$
\begin{aligned}
& R N_{x, x}+N_{x \theta, \theta}=0, \\
& R N_{x \theta, x}+N_{\theta, \theta}=0, \\
& D \triangle \triangle w+\frac{1}{R} N_{\theta}-\left[N_{x} w_{, x x}+\frac{2}{R} N_{x \theta} w_{, x \theta}+\frac{1}{R^{2}} N_{\theta} w_{, \theta \theta}\right]=0
\end{aligned}
$$

where

$$
D=\frac{E_{1} E_{3}-E_{2}^{2}}{E_{1}\left(1-\nu^{2}\right)}, \triangle=\frac{\partial^{2}}{\partial x^{2}}+\frac{1}{R^{2}} \frac{\partial^{2}}{\partial \theta^{2}} .
$$

For a slightly imperfect shell, let $w^{*}(x, \theta)$ denotes a known small imperfection. This parameter represents a small deviation of the shell middle plane from a flat shape. According to [1], equilibrium equations for the imperfect FG shell are as

$$
\begin{aligned}
& R N_{x, x}+N_{x \theta, \theta}=0, \quad R N_{x \theta, x}+N_{\theta, \theta}=0, \quad D \Delta \Delta w+\frac{1}{R} N_{\theta} \\
& -\left[N_{x}\left(w_{, x x}+w_{, x x}^{*}\right)+\frac{2}{R} N_{x \theta}\left(w_{, x \theta}+w_{, x \theta}^{*}\right)+\frac{1}{R^{2}} N_{\theta}\left(w_{, \theta \theta}+w_{, \theta \theta}^{*}\right)\right]=0 .
\end{aligned}
$$

The stability equations of the shell may be derived by the adjacent equilibrium criterion [1] as follows

$$
\begin{aligned}
& R N_{x 1, x}+N_{x \theta 1, \theta}=0, \quad R N_{x \theta 1, x}+N_{\theta 1, \theta}=0, \\
& D \triangle \triangle w_{1}+\frac{1}{R} N_{\theta 1}-N_{x 0} w_{1, x x}-\frac{2}{R} N_{x \theta 0} w_{1, x \theta}-\frac{1}{R^{2}} N_{\theta 0} w_{1, \theta \theta}- \\
& {\left[N_{x 1}\left(w_{0, x x}+w_{, x x}^{*}\right)+\frac{2}{R} N_{x \theta 1}\left(w_{0, x \theta}+w_{, x \theta}^{*}\right)+\frac{1}{R^{2}} N_{\theta 1}\left(w_{0, \theta \theta}+w_{, \theta \theta}^{*}\right)\right]=0 .}
\end{aligned}
$$

In Eqs. (10), terms with the subscript ' 0 ' are related to the state of equilibrium and terms with the subscript ' 1 ' are those characterizing the state of stability.

The Wan-Donnell model for the radial imperfection is $[1,2]$

$$
w^{*}=\frac{K-1}{2} w,
$$

where the coefficient $K$ is a constant value $0 \leqslant K \leqslant 1$. The value of $K=1$ represents a perfect shell. The imperfection $w^{*}$ is thus defined as a function of $w$, the lateral deflection of the FG cylindrical shell. Considering an axisymmetric imperfection, due to the dependency of $w$ to $w^{*}$, the lateral deflection $w$ must be assumed to be axisymmetric. This assumption results in an axisymmetric buckling mode of the FG cylindrical shell, such that

$$
w^{*}=w^{*}(x), \quad w_{0}=w_{0}(x), \quad w_{1}=w_{1}(x) .
$$

The prebuckling force resultants of FG shell under thermal load are determined as $[2,12]$

$$
N_{x 0}=-\frac{\Phi}{1-\nu}, \quad N_{\theta 0}=0, \quad N_{x \theta 0}=0 .
$$

Putting Eqs. (12), (13) into Eqs. (9) and (10) gives the equilibrium equation

$$
D w_{0, x x x x}-N_{x 0}\left(w_{0, x x}+w_{, x x}^{*}\right)=0,
$$

and the stability equation

$$
D w_{1, x x x x}+\frac{1}{R} f_{, x x}-N_{x 0} w_{1, x x}-f_{, y y}\left(w_{0, x x}+w_{, x x}^{*}\right)=0
$$


of the axisymmetric imperfect FG cylindrical shell, where a change of variable $y=R \theta$ and a stress function $f(x, y)$ has been used, such as

$$
N_{x 1}=f_{, y y}, N_{y 1}=f_{, x x}, N_{x y 1}=-f_{, x y} .
$$

Equation (15) is the Wan-Donnell stability equation of an imperfect FG cylindrical shell. This equation includes two dependent functions, $w_{1}$ and $f$. To obtain a second equation relating the dependent functions $w_{1}$ and $f$, the compatibility equation may be used, as follows

$$
\varepsilon_{x m 1, y y}+\varepsilon_{y m 1, x x}-\gamma_{x y m 1, x y}=0,
$$

where $\varepsilon_{x m 1}, \varepsilon_{y m 1}, \gamma_{x y m 1}$ denote parts of the strain components which are linear in stability state displacements $u_{1}, v_{1}, w_{1}$. These strains may be written in terms of the displacement components, using Eqs. (6) with consideration of the imperfection term $w^{*}$, as

$$
\begin{aligned}
\varepsilon_{x m 1} & =u_{1, x}+\left(w_{0, x}+w_{, x}^{*}\right) w_{1, x} \\
\varepsilon_{y m 1} & =v_{1, y}+w_{1} / R+\left(w_{0, y}+w_{, y}^{*}\right) w_{1, y} \\
\gamma_{x y m 1} & =u_{1, y}+v_{1, x}+\left(w_{0, x}+w_{, x}^{*}\right) w_{1, y}+\left(w_{0, y}+w_{, y}^{*}\right) w_{1, x} .
\end{aligned}
$$

Moreover, from the constitutive relations (3), one can write for stability state as

$$
\begin{aligned}
\varepsilon_{x m 1} & =\frac{1}{E_{1}}\left(N_{x 1}-\nu N_{y 1}-E_{2} k_{x 1}+\Phi\right), \\
\varepsilon_{y m 1} & =\frac{1}{E_{1}}\left(N_{y 1}-\nu N_{x 1}-E_{2} k_{y 1}+\Phi\right), \\
\gamma_{x y m 1} & =\frac{2}{E_{1}}\left[(1+\nu) N_{x y 1}-E_{2} k_{x y 1}\right] .
\end{aligned}
$$

From Eqs. (17), (18), (19), taking into consideration Eqs. (12), (16), we obtain equation

$$
\frac{1}{E_{1}} \triangle \triangle f=\frac{1}{R} w_{1, x x}
$$

Equations (14), (15) and (20) are the basic equations used to obtain the critical buckling loads of imperfect FG cylindrical shells. By putting $k=0$, these equations turn into respective ones in [2] for imperfect isotropic and homogeneous shells.

\subsection{Buckling of imperfect functionally graded shells under uniform tempera- ture rise}

Consider a imperfect cylindrical shell of thickness $h$ and length $L$ made of functionally graded material. The ends are assumed to be simply supported, where the boundary conditions at $x=0$ and $x=L$ are

$$
w=w_{, x x}=0
$$

The lateral imperfection of the shell may be assumed to be

$$
w^{*}=\frac{(K-1) \zeta}{2} \sin \frac{m \pi x}{L}
$$

where $\zeta$ is the imperfection size.

Substituting $N_{x 0}$ from (13) into (14) and assuming a solution in the form

$$
w_{0}=A \sin \frac{m \pi x}{L}
$$


which satisfies the simply supported edge conditions at $x=0$ and $L$, the constant $A$ is obtained and the final approximate solution of Eq. (14) is

$$
w_{0}=\frac{(K-1) \Phi \zeta}{2 D(1-\nu)\left(\frac{m \pi}{L}\right)^{2}-2 \Phi} \sin \frac{m \pi x}{L} .
$$

Substituting $w_{0}$ and $w^{*}$ into Eqs. (15) and (20) yields

$$
\begin{aligned}
& R_{1} \equiv D w_{1, x x x x}+\frac{1}{R} f_{, x x}+\left[\frac{\Phi}{1-\nu} w_{1, x x}+(A+H)\left(\frac{m \pi}{L}\right)^{2} f_{, y y} \sin \frac{m \pi x}{L}\right]=0 \\
& R_{2} \equiv \frac{1}{E_{1}} \triangle \triangle f-\frac{1}{R} w_{1, x x}=0,
\end{aligned}
$$

where $H \equiv \frac{(K-1) \zeta}{2}$

To solve the system of Eqs. (25), with the consideration of the boundary conditions, the approximate solutions are assumed

$$
\begin{aligned}
w_{1} & =E_{m} \sin \frac{m \pi x}{L}, \\
f & =F_{m} \sin \frac{m \pi x}{L} \cos \frac{y}{R}, 0 \leqslant x \leqslant L ; 0 \leqslant y \leqslant 2 \pi R,
\end{aligned}
$$

where $E_{m}, F_{m}$ are constant coefficients. Applying the Galerkin mehtod to the system of equation (25). The system of Eqs. (25) yields

$$
\begin{aligned}
& \int_{0}^{2 \pi R} \int_{0}^{L} R_{1} \sin \frac{m \pi x}{L} \cos \frac{y}{R} d x d y=0 \\
& \int_{0}^{2 \pi R} \int_{0}^{L} R_{2} \sin \frac{m \pi x}{L} d x d y=0
\end{aligned}
$$

where $R_{1}, R_{2}$ designate the left sides of Eq. (25) known as the residues of Galerkin method. The determinant of the system of Eqs. (27) for the coefficients $E_{m}$ and $F_{m}$ is set to zero, which yields

$$
\Phi_{\text {min }}=\frac{D(1-\nu) \pi}{L^{2}}\left(\frac{8 H}{3 R}+\pi\right),
$$

obtained with $m=1$. The smallest value of $\Delta T$ is obtained using Eqs. (5) and (28)

$$
\Delta T_{c r}=\frac{D(1-\nu) \pi}{P L^{2}}\left(\frac{8 H}{3 R}+\pi\right)
$$

where

$$
P=E_{m} \alpha_{m} h+\left(E_{m} \alpha_{c m}+E_{c m} \alpha_{m}\right) \frac{h}{k+1}+E_{c m} \alpha_{c m} \frac{h}{2 k+1} .
$$

\subsection{Buckling of imperfect FG shell under nonlinear temperature change across the thickness}

The steady state heat conduction equation and the related boundary conditions

$$
\frac{d}{d z}\left(K(z) \frac{d T}{d z}\right)=0,\left.T(z)\right|_{z=-h / 2}=T_{m},\left.T(z)\right|_{z=h / 2}=T_{c},
$$

where $T_{c}$ and $T_{m}$ are the temperature of ceramic-rich and metal-rich surfaces, respectively. The solution of Eq. (31) is obtained by means of polynomial series. Taking the first seven 
terms of the series [16], the solution for temperature distribution across the shell thickness becomes

$$
T(z)=T_{m}+\frac{\Delta T \cdot r \cdot \sum_{n=0}^{6}\left[\left(-r^{k} \cdot K_{c m} / K_{m}\right)^{n} /(n k+1)\right]}{\sum_{n=0}^{6}\left[\left(-K_{c m} / K_{m}\right)^{n} /(n k+1)\right]},
$$

where $\Delta T=T_{c}-T_{m}$ and $r=(2 z+h) / 2 h$.

Putting (32) into (5) and from (28) we obtain

$$
\Delta T_{c r}=\frac{D(1-\nu) \pi}{Q L^{2}}\left(\frac{8 H}{3 R}+\pi\right)
$$

where

$$
Q=\frac{\sum_{n=0}^{n=6}\left[\left(-K_{c m} / K_{m}\right)^{n} /(n k+1)\right]}{h \sum_{n=0}^{n=6} \frac{\left(-K_{c m}\right)^{n}}{K_{m}^{n}(n k+1)}\left[\frac{E_{m} \alpha_{m}}{n k+2}+\frac{E_{m} \alpha_{c m}+E_{c m} \alpha_{m}}{(n+1) k+2}+\frac{E_{c m} \alpha_{c m}}{(n+2) k+2}\right]}
$$

\section{RESULTS AND DISCUSSION}

The thermal buckling loads of the imperfect functionally graded cylindrical shell are obtained in closed form solutions for the assumed thermal loadings and represented by Eqs. (29) and (33). These equations indicate that the critical buckling temperature change of an imperfect FG shell is decreased in comparision with a perfect one. The decrease in $\Delta T_{c r}$ is expressed by an negative imperfection term $8 H / 3 R$, which directly depends on the imperfection size $\zeta$.

As an example, consider an imperfect ceramic-metal FG shell that consists of aluminum and alumina with following properties $[4,12,16]$

$$
\begin{array}{r}
E_{m}=70 G P a, \alpha_{m}=23 \times 10^{-6} /{ }^{0} C, K_{m}=204 \mathrm{~W} / \mathrm{mK}, \\
E_{c}=380 G P a, \alpha_{c}=7.4 \times 10^{-6} /{ }^{0} C, K_{c}=10.4 \mathrm{~W} / \mathrm{mK}, \nu=0.3 .
\end{array}
$$

The shell is assumed to be simply supported on two ends. The variation of $\Delta T_{c r}$ versus the relative thickness $h / R$ for two types of thermal loadings is shown in Figs. 1 and 2. These Figs. indicate that the critical thermal loads are increased when the thickness increases. The pure ceramic shell $(k=0)$ is remarkably more stable than graded shells, moreover, the greater power law index $k$ to be, the smaller value of critical thermal loads become for FG shells. This is expected because ceramic-rich shell withstands temperature better than metal-rich one. Especially, FG shell under nonlinear thermal gradient is considerably more stable than under uniform temperature rise.

In Fig. 3, a variation of critical thermal loads versus relative thickness with different imperfection sizes for uniform temperature rise is plotted. It is observed that the critical thermal loads decrease when imperfection sizes to be larger. This is good agreement, in tend, of present result with those reported in [2] for imperfect isotropic circular cylindrical shell under thermal loads. 


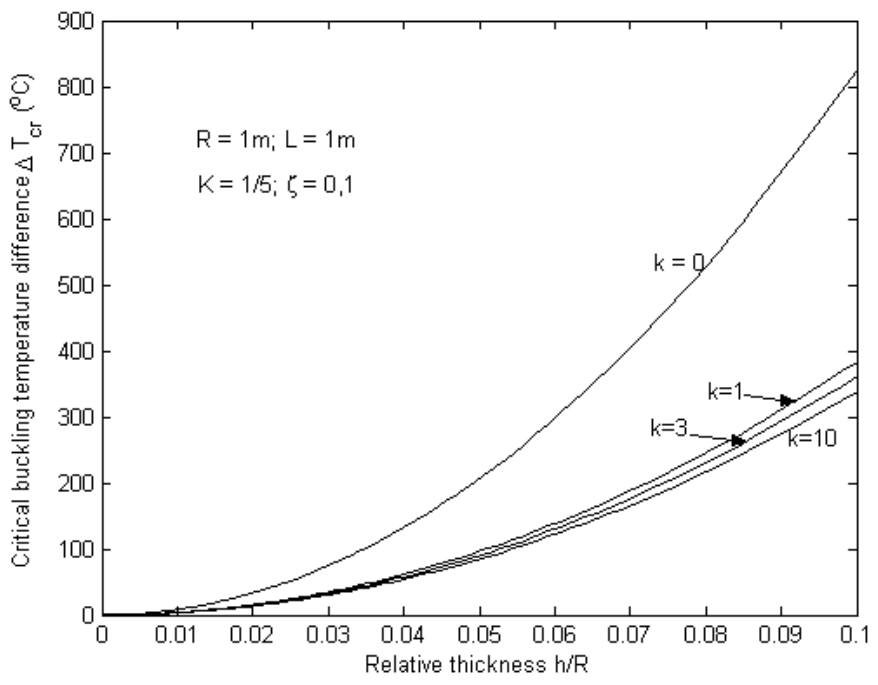

Fig. 1. Critical buckling temperature change of FG shell under uniform temperatue rise versus $h / R$ and power law index

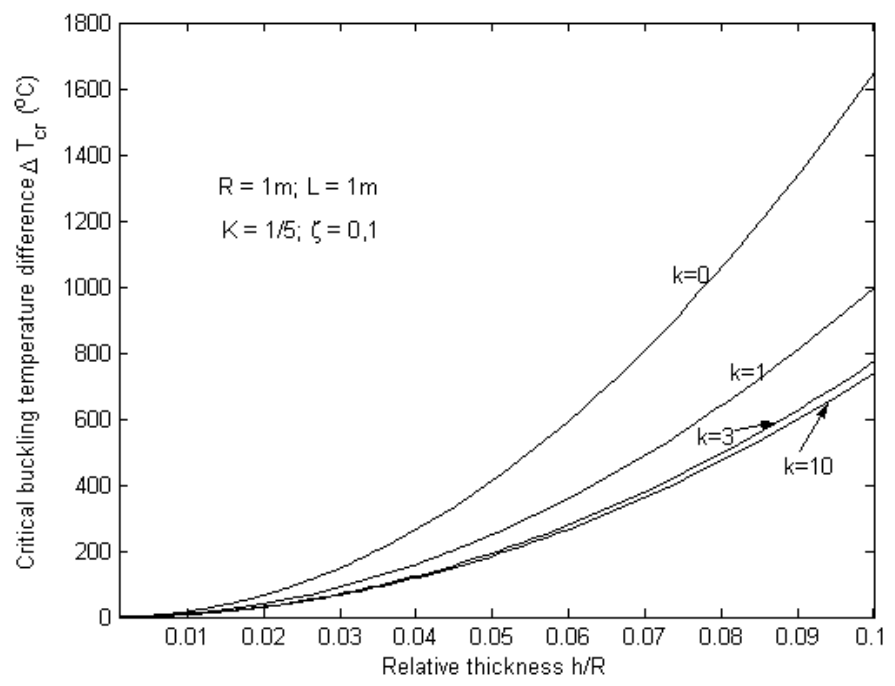

Fig. 2. Critical buckling temperature change of FG shell under nonlinear thermal gradient across the thickness versus $\mathrm{h} / \mathrm{R}$ and power law index

\section{CONCLUSIONS}

In the present paper, equilibrium, stability, and compability equations for an imperfect functionally graded cylindrical shell are derived. Derivations are based on the Donnell shell theory and the assumption of power law composition for the constituent materials. The imperfection of the shell is assumed to be axisymmetric and follows Wan-Donnell model. 


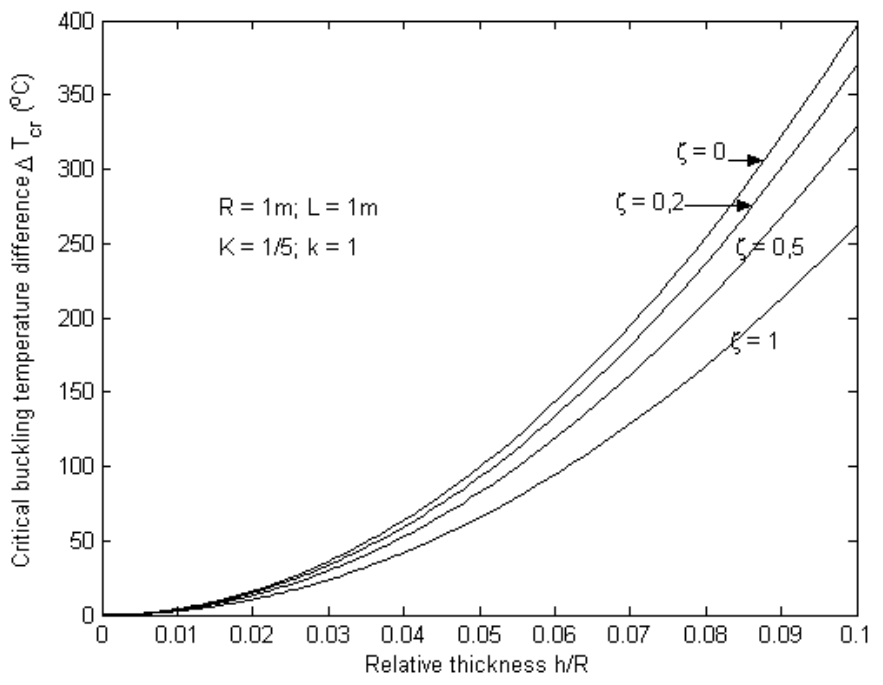

Fig. 3. Critical buckling temperature change of FG shell under uniform temperatue rise versus $\mathrm{h} / \mathrm{R}$ and imperfection amplitude

The buckling analysis of such a shell under two types of thermal loadings is investigated. The shell buckles at first mode and the followings are concluded:

(1) The critical buckling temperature change, $\Delta T_{c r}$, of an imperfect FG shell is smaller than a perfect one. This decrease is directly indicated in closed form solutions of critical loads.

(2) $\Delta T_{c r}$ of a FG shell decreases with the increase of imperfection size $\zeta$.

(3) $\Delta T_{c r}$ of an imperfect FG cylindrical shell increases with the increase of the relative thickness $h / R$. In contrast, $\Delta T_{c r}$ of imperfect $\mathrm{FG}$ shell is reduced when the power law index $k$ increases. The reduction from $k=0$ to $k=1$ is considerable. However, for $k>1$, it is marginal.

(4) $\Delta T_{c r}$ of the shell subjected to nonlinear temperature change across the thickness is considerably greater than the one subjected to uniform temperature rise.

\section{ACKNOWLEDGMENT}

The results of researching presented in the paper have been performed according to scientific research project of Vietnam National University, Hanoi, coded QGTĐ.08.07. The authors gratefully acknowledge this financial support.

\section{REFERENCES}

1. D. O. Brush, B. O. Almroth, Buckling of Bars, Plates and Shells, McGraw-Hill, New York, 1975.

2. M. R. Eslami, R. Shahsiah, Thermal buckling of imperfect cylindrical shells, Journal of Thermal Stresses 24 (1) (2001) 71-89.

3. M. R. Eslami, M. Shariyat, Elastic, plastic and creep buckling of imperfect cylinders under mechanical and thermal loadings, Journal of Pressure Vessel Technology, Transactions of the ASCE 119 (1) (1997) 27-36.

4. R. Javaheri, M. R. Eslami, Thermal buckling of functionally graded plates, AIAA Journal 40 (1) (2002) 162-169. 
5. R. Javaheri, M. R. Eslami, Buckling of functionally graded plates under in-plane compressive loading, ZAMM Journal 82 (4) (2002) 277-283.

6. R. Javaheri, M. R. Eslami, Thermal buckling of functionally graded plates based on higher order theory, Journal of Thermal Stresses 25 (1) (2002) 603-625.

7. C. A. Meyers, M. W. Hyer, Thermal buckling and postbuckling of symmetrically laminated plates, Journal of Thermal Stresses 14 (1991) 519-540.

8. A. Mossavarali, M. R. Eslami, Thermoelastic buckling of plates with imperfections based on higher order displacement field, Journal of Thermal Stresses 25 (8) (2002) 745-771.

9. A. Mossavarali, Gh. Peydeye Saheli, M. R. Eslami, Thermoelastic buckling of isotropic and orthotropic plates with imperfections, Journal of Thermal Stresses 23 (2000) 853-872.

10. K. D. Murphy, D. Ferreira, Thermal buckling of rectangular plates, International Journal of Solids and Structures 38 (2001) 3979-3994.

11. J. N. Reddy, C. D. Chin, Thermomechanical analysis of functionally graded cylinders and plates, Journal of Thermal Stresses 21 (1998) 593-626.

12. R. Shasiah, M. R. Eslami, Thermal buckling of functionally graded cylindrical shell, Journal of Thermal Stresses 26 (3) (2003) 277-294.

13. R. Shasiah, M. R. Eslami, Functionally graded cylindrical shell thermal instability based on improved Donnell equations, AIAA Journal 41 (9) (2003) 1819-1824.

14. H. Shen, Thermal postbuckling of functionally graded cylindrical shells with temperature dependent properties, International Journal of Solids and Structures 41 (2004) 1961-1974.

15. E. A. Thorton, Thermal buckling of plates and shells, Applied Mechanics Review 46 (10) (1993) 485-506.

16. Lanhe Wu, Zhiqing Jiang, Jun Liu, Thermoelastic stability of functionally graded cylindrical shells, Journal of Composite Structures 70 (2005) 60-68.

Received December 8, 2008

\section{ỔN ĐỊNH NHIỆT ĐÀN HỒI CỦA VỎ TRỤ BIẾN ĐỔI CHỨC NĂNG KHI CÓ IMPERFECT BAN ĐẦU THEO MÔ HİNH WAN-DONNELL}

Bài báo này nghiên cứu ổn định nhiệt đàn hồi của vỏ trụ tròn làm từ vật liệu biến đổi chức năng khi có imperfect ban đầu. Các phương trình cân bằng và ổn định được thiết lập dựa trên lý thuyết vỏ Donnell và mô hình Wan-Donnell cho imperfect hình học ban đầu được xét. Hai trường hợp tải nhiệt được nghiên cứu là sự tăng nhiệt độ đồng nhất của môi trường chứa vỏ trụ và sự truyền nhiệt qua chiều dày của vỏ trụ. Biểu thức giải tích cho nhiệt độ tới hạn của hai trường hợp tải nhiệt được đưa ra đối với vỏ trụ tựa bản lề ở hai đầu. Tính chất của vật liệu chức năng được giả thiết biến đổi theo chiều dày vỏ theo một hàm mũ. Những ảnh hưởng của độ dày tương đối của vỏ, cỡ imperfect ban đầu và chỉ số luật mũ lên tải nhiệt tới hạn được nghiên cứu và thảo luận. 